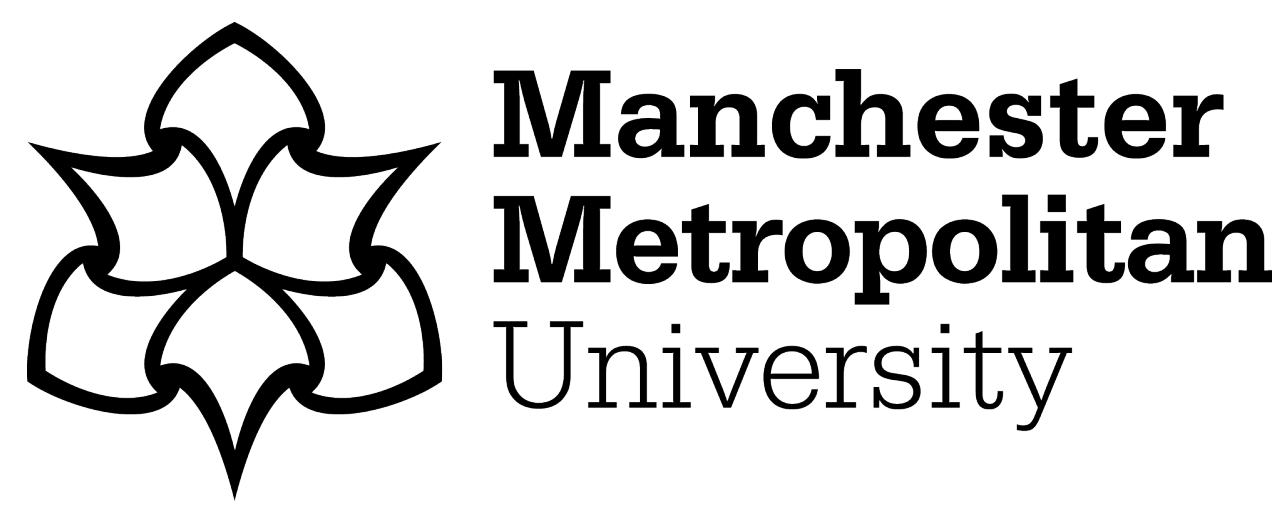

Challis, B ORCID logoORCID: https://orcid.org/0000-0002-0200-8087 and Dean, R (2014) Defining digital-Foley for live performance. International Journal of Arts and Technology, 7 (4). pp. 339-355. ISSN 1754-8853

Downloaded from: https://e-space.mmu.ac.uk/891/

Version: Accepted Version

Publisher: Inderscience

DOI: https://doi.org/10.1504/IJART.2014.066453

Please cite the published version 


\title{
Defining digital-Foley for Live Performance
}

\author{
Ben Challis \\ Cardiff School of Creative and Cultural Industries, \\ University of South Wales, \\ Cardiff, UK \\ E-mail: ben.challis@southwales.ac.uk
}

\section{Rob Dean}

Cardiff School of Creative and Cultural Industries, University of South Wales,

Cardiff, UK

E-mail: rob.dean@southwales.ac.uk

\begin{abstract}
Using a series of reflective case-studies, the role of the Foley artist is reconsidered alongside technological innovations in both digital soundmanipulation and physical computing. Through a series of theatrical productions and collaborations Challis and Dean have explored the sonic and dramatic possibilities created by the utilisation of digital technology in a live performance context. In this article, a variety of approaches to electronic sound-production and control are described along with first-hand reflections on the expressivity and control that are offered by each within a context of live drama. Their current project is a multimedia adaptation of the novel and film Metropolis where the aural accompaniment will be performed live using a range of adapted and purpose built sonic triggers. In defining digital-Foley, design considerations and key principles are outlined that can enhance the connectivity between the sound-artist and the sonic-landscapes they create.
\end{abstract}

Keywords: Technology; theatre; drama; liveness; sound; music; digital-Foley

Biographical notes: Ben Challis is a composer, performer and technologist. With research interests that embrace the notion of design-for-all within musicperformance, he has worked on various projects that explore alternative modes of interaction with sound and music for people with specific individual needs. As a performer, he works with these same technologies, exploring their creative and expressive potential within free-improvisation. As a composer he has written scores for film, theatre and radio productions. He is currently a Senior Lecturer and Joint Award Leader in Popular Music at the University of Glamorgan, ATRiuM.

Rob Dean is a Lecturer in Drama, Theatre and Media at the University of South Wales. His research into musical dramaturgy and the history of sound production has resulted in publications that reconsider the role of sonic material in the works of Ibsen, Chekhov, Boucicault, and Shaw. Other published work includes a consideration of ethics and catechism in 'The Walking Dead', and the development of representations of Batman within gaming culture. Recent practical research explores the potentiality of digital Foley within live performance. 


\section{Introduction}

The term Foley is most commonly associated with its current modern application within the film industry. In this context it is the creation of sound effects for a film which takes place as part of the post-production process. As such, while the effect may be created 'live' in the studio, not only is it a response to pre-recorded material, the sounds themselves will ultimately be captured, edited, re-mixed, and synchronised with the visual stimuli. However, the role of creating sounds to accompany a dramatic work is not limited to the filmic medium, nor is it dependent on the ability to synchronise recorded sound with the moving image.

Although sound could not be separated from its source before the invention of sound recording, since the time of ancient Greece, theatre makers have created contraptions to simulate sounds. Heron of Alexandria invented a machine to replicate thunder which consisted of a metal box, containing a set of staggered metal shelves, and a trapdoor, above which a set of brass balls were placed. Opening the trapdoor released the balls, which would crash onto the shelves and come to rest on a tin sheet at the bottom of the box. The 'Onomastikon' also mentions that the sound of thunder was created by means of "bags full of pebble-stones poured into a brazen vessel" (Nagler 1952).

Another technique for making thunder was invented in 1708 by John Dennis who designed it for use in his play 'Appius and Virginia'. Dennis used a sheet of copper suspended by wires. The effect was created by holding the copper sheet at the edge and shaking it vigorously; the harder it is shaken the louder the effect. The thunder-sheet, like many other Foley devices, remained in use throughout the nineteenth and twentieth century.

The techniques used to create live sound effects in the theatre where also employed and adapted for the production of radio drama. As a non-visual medium, radio is entirely dependent on aural signs to communicate the setting in which the drama unfolds as well as the people who populate it and the objects they use. Because the Foley artist's contribution was central and essential in the performance of radio drama the medium is often credited with establishing the artistic credentials of this type of accompaniment. Mott asserts: "The art of sound effects began when radio and film were first struggling for recognition ... the use of sound effects has evolved from the early days of radio to the art form it is today" (Mott 1990). While Mott's assertion does not fully take into account the extent to which this evolution was initiated and maintained in the Theatre, the importance of the Foley artist in the production of Radio Drama is unquestionable. Mott then goes on to cite the benefits of late twentieth century recording technology:

\footnotetext{
"Therein lies the tremendous advantage that effects on tape have over effects that are done live. With taped effects, you will hear the same sound in the exact same manner every time it is played. With live effects, there are never any guarantees. This is especially true of creating sounds that require a certain amount of pressure or friction to produce a desired effect." (ibid, 121)
}

However, despite these advantages the switch from live to recorded sound also dismantled the responsive relationship that existed between those that perform sound and those that receive it. The live creation of sounds allows the Foley artist to respond intuitively to the ebb, flow, and rhythm of a live performance. In contrast, using recorded sound often 
reduces the role to that of an operator who simply sets the volume and presses the play button on cue.

Of course, in many ways the benefits of working with recorded sound justifies this shift in procedure and production. Recorded sound can be manipulated, tweaked, edited and subtly mixed. Far more realistic sound-effects can be produced with the use of modern recording technology. Moreover, this way of working is a dependable and efficient alternative to employing a team of Foley artists, and musicians, to perform the sonic accompaniment each time the work is presented. Indeed as Mott points out "... manual effects require the use of hands or feet. Inasmuch as sound effects artists are merely human, he or she can perform just so many effects at a given time" (ibid, 124).

This description of the live Foley artist is an important reminder that they were performers, playing an orchestra of sound objects to create sonic response to actions or events. The notion of performance is key within this and analogies can be drawn between musicians (as performers) and Foley artists as performers. Both employ skill-based performance behaviours where the sound produced is directly related to the performers own actions with physical gestures mapping onto sonic outcomes. Both also operate with a certain level of uncertainty, the potential to miss-hit or under-play a particular note or sound but, equally, the facility to quickly adjust and fine-tune the outcome to make amends. In music, this offers the performer scope to react and adjust to the sound of other instruments within improvised music and in Foley it offers the performer similar scope to react and adjust to events unfolding in a live environment.

\section{Reflections on practice}

\subsection{Initial Experiments}

In considering how novel approaches to audio manipulation within the digital domain might enhance the sonic palette of the Foley artist, it is important that those techniques and effects that might be regarded as 'traditional' should also be explored within this same process. With this in mind, the various reflections on practice being described in the following sections have been informed greatly by a number of other performance experiences where the focus has been placed on gaining experiential insight into the opportunities and demands this type of live interaction creates. This has included Challis and Dean taking part in the production of three live radio dramas which re-created the performance conditions of the nineteen-thirties (The Terrifying Tale of Sweeney Todd!, 2008; The Casebook of Violet Strange, 2010; Lover's Lane, 2013). Performing the sound and music live encouraged and necessitated a high level of symbiosis between director, actors, musicians, Foley artists, and engineers. Each discrete element, be it a voice, an instrument, or running on the spot a-top a Foley footstep box, had to work in unison. This reflexive relationship was based upon intuition, practice, and design. The script, musical score, and sound effects devices had been written, composed, or built. These 'designs' were put into practice through rehearsal. Finally, in performance, the cues, techniques, artistic touches and set pieces were intuitively executed in response to the live interplay between sonic components. Although these radio projects highlighted the possibilities and processes live sound facilitates, they also underlined the restrictions and problems modern technology has overcome. It is this disjunction between the potential of live sonic accompaniment and the practicality of recorded sound that digital-Foley seeks to resolve. 
Technological advances over the past quarter of a century have produced a range of options and techniques for triggering, mapping, and manipulating digital sound which can be used to enhance expressivity and connectivity between the sound-artist, the stimuli they respond to, and the sonic-landscapes they create. Rapid growth within the games industry has contributed greatly to the overall availability and accessibility of such novel devices with the emergence of highly sophisticated yet very affordable sensor-based technologies aimed almost exclusively at a domestic market. By way of example, the Nintendo Wiimote game controller is a handheld wireless device that offers an array of switches, a joystick, a joypad, vibratory feedback and sensors that can monitor independent hand position and movement across three axis. Alternatively, Microsoft's Kinect game controller uses a combination of laser projection and infrared detection to offer realtime monitoring of movement across a relatively large area such that quite complex gestures can be recognised and responded to.

Though aimed primarily at the home entertainment market, digital artists have quickly recognised the potential for repurposing these devices as instrument-like controllers for computer-based performances and the communities behind arts-based development environments like Processing, Pure Data and Max/Msp have readily created the software plug-ins that can enable these opportunities. Alongside these developments, the Arduino microcontroller development system offers easy access to a wide variety of sensors for exploring physical computing, enabling digital artists to create their own unique performance interfaces. Francese et al. (2012) and Barbancho et al. (2013) present detailed assessments of the Wiimote and Kinect as gestural input devices and there are many examples where these, and similar gaming technologies, have been incorporated into a wide variety of performance contexts including sonic art (Paine 2007, Yoo et al. 2011), music therapy (Beneviste et al. 2009), virtual instruments (Miller and Hammond 2010, Wong et al. 2008), improvised music (Senturk et al. 2012), dance (Jung et al. 2012) and theatre (Schofield et al. 2013).

Using similar technologies to those just described, the digitally augmented Foley artist can react to events unfolding in a live environment and adjust both subtle and prominent aspects of the sound in many of the ways a musician can. Using adapted and purpose built sonic triggers (accelerometers, gyroscopes, tilt switches, micro controllers, and proximity sensors) the digital-Foley artists can trigger sounds and manipulate sonic parameters with direct physical contact (bending, stretching, hitting, and squeezing) and other intuitive interactions. The following sections describe a practice-as-research based approach to understanding how interactive techniques can be used to more effectively open up the digital domain to the Foley artist. Based on personal experiences of using innovative technologies for sound control in theatre productions, three central case-studies are presented that demonstrate the potential for digital-Foley in live performance. In analysing and reflecting upon these initial attempts, this paper outlines the principles and possibilities of a process which allows forms of connectivity between the performer, the Foley artist, and the sounds they produce.

\subsection{Case Study 1: Crash}

In 2001 Dean worked as sound designer on an adaptation of J.G. Ballard's novel Crash (1973). In addition to triggering a range of pre-recorded sound clips, a number of more experimental approaches were adopted, three of which are of particular relevance to this paper. Firstly, the director (David Ian Rabey) made the decision to have Dean and his 'instruments' visible to the audience rather than placing him behind a screen or in the 
lighting box. This positioning not only enabled the audience to see the sound designer and his kit (a visual representation of turning conventions inside-out that chimed with the expressionistic production values of the play), it also allowed the sound designer a close, panoramic view of the audience and performers.

Secondly, as a way of rendering the sounds of car engines in a non-naturalistic way Dean experimented with a Theremin during rehearsals. The Theremin was connected to a guitar effects processor into which he programmed four effects that mimicked the growl and pulse of a car engine. The speeds of the oscillations were controlled by a 'wah-wah' pedal. In the citation below Rabey describes the effect this created and the performative interplay between Dean and the actors: "The expressionistic choreography and physical 'score' of the production incorporated many careful actions (some mimed, some not) of sculpting, grooming, tracing, delineating, dancing, caressing, puppeteering, mirroring, [and] counter tension ... They were further developed in response to ... non-musical sound cues ... designed to follow, rather than dictate, performers' movements, extending the improvisatory dimension of the soundscape. Dean introduced a Theremin into rehearsals, with which he could suggest the acceleration of cars into a non-naturalistic way, accompanying the performers' 'driving' movements by observing and mimicking their tempo of moves with movement of his own hand within the sonic orbit of the Theremin." (Rabey 2003)

Another Foley device consisted of a large iron sheet with a microphone attached to the base which was hung from the ceiling by a thin wire. When the metal was struck with a timpani mallet it would make a sound like a dull gong, however Dean used it to create a more visceral sonic effect. He attached four long shards of aluminium to the fingers of a leather work glove. By delicately stroking these sharply tipped 'Kruegeresque' digits along the metal plate Dean created "... the sort of noise conventionally described as 'putting one's teeth on edge" " (ibid, 45). The sound was captured by a floor mic beneath the iron plate and played back through four speakers arranged around the audience to create a quadraphonic effect.

When the actors performed physical representations of the character Vaughan inflicting harm on himself by scratching themselves and picking at imaginary scabs Dean would mimic the speed, trajectory, intensity, and rhythm of their movements with the aluminium scrapers. The sound had a clear physical effect on the audience, causing them to wince, groan, and cover their ears. While some of the performers could not bear the sound, others built up a certain degree of tolerance and through the rehearsal process intuitively learnt which movements produced the effects that caused the most discomfort to others. These performers became directly complicit in this act of sonic torture and would maintain direct eye contact with Dean in order to effectively play the metallic instrument by proxy.

\subsection{Case Study 2: Dead by Dawn}

In February 2009, Challis and Dean collaborated on Dead by Dawn; a stage play based on Sam Rami's Evil Dead films. While performance techniques, lighting states, make-up and hidden trapdoors all contributed to the effectiveness of the production, the sonic material and the manner in which it was manipulated played a central role. The production was designed to include live sound manipulation by a small group of musicians/Foley artists with the aim of creating a cinematic soundtrack within a theatrical environment and combining performance elements of Foley with the digital manipulation of sounds.

The Foley artists were positioned on a balcony from which they could see both the stage and the conductor. This viewpoint enabled them to quickly become familiar with the 
dialogue, movements and effects that prompted certain sounds and sonic states. Once these visual markers had been learnt the musicians were able to mould their sonic accompaniment around them. As such the action on stage was not shackled to a fixed sonic composition thereby granting the performers a level of autonomy as the musicians could respond to variations in duration and delivery. During some moments a kind of emotive circuit was created; the sound of an evil force approaching produced a response of terror from a performer, this caused the musicians to intensify the sound, which in turn prompted the performer to heighten their response and so on. This relationship continued to evolve throughout the rehearsals and performances. With each run, the connection between the events on stage and the sonic accompaniment became stronger. Two examples which illustrate the opportunities this approach created were a chainsaw attack and the suggestion of evil voices plaguing the main character.

Rather than using conventional control methods Challis adopted an alternative approach to sound control thereby enhancing his ability to match and react to the characters' actions. A sound-controller designed by Challis (2008) was adapted and reconfigured to work with specific sound-sets.

The instrument which served as the prototype for exploring and experimenting with digital-Foley was the 'Benemin' (see fig. 1).

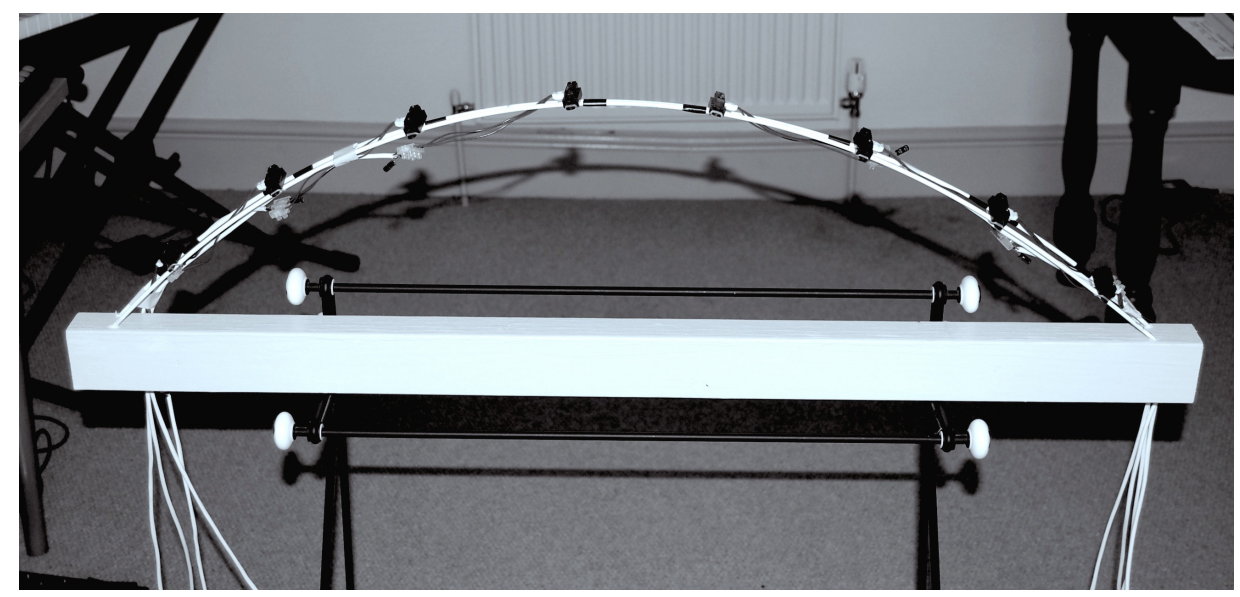

Figure 1 Prototype 'Benemin' - used as a controller for sound manipulation in Dead by Dawn.

The Benemin is a gesture-based sound controller initially designed and built by Challis as a means of providing intuitive access to musical activities for individuals with special needs. Its design is relatively simple, using eight proximity sensors arranged in a nearhorizontal format in front of the performer and drawing on technology that was first explored within the "Dimension Beam"; originally manufactured by the US company "Interactive Light", this device mapped musical notes to a single 'beam' via MIDI using an infrared light sensor. These sensors can tend to trigger one another when used in close proximity but a study by Brooks et al. (2002) successfully incorporated three Dimension Beams into an array that enabled individuals with severe learning difficulties to interact with sounds and images. The Benemin, took this concept further ultimately using a large enough array to enable a diatonic musical instrument to be created. 
Each sensor in the Benemin acts as an interactive 'beam' which can be triggered by a hand (finger, arm, foot) and in its original design, this would play one note from a given scale with subsequent movement up and down within the beam affecting the volume or tone of that particular note. In its adapted form it was employed as a controller, with individual beams being mapped to audio-loops and processes thereby enabling the performer to glide rapidly across complex sound sets whilst still maintaining expressive control over the output. To allow sounds to be triggered and manipulated in this way, software programming environments (MAX/MSP by Cyling74 and Reaktor by Native Instruments) were used to create synthesis engines which could be loaded as predefined 'instruments'.

In the production, Challis used the Benemin to digitally manipulate and mix recorded sound-effects in response to the live action on stage and the sonic responses of the other musicians / digital-Foley artists. Primarily, it enabled Challis to create and perform highly atmospheric and complex layered soundscapes with a level of expressivity and connectivity that would not have been possible through more conventional approaches. For instance, one scene depicting a character's possession by an invisible evil force was accompanied (and to a certain degree directed) by the sonic manifestation of its malignant presence. Processed animal sounds, strange voices, and sudden door slams were mapped across each of the Benemin's six sensors in such a way that they corresponded to spatial locations placed across a stereo field. This allowed Challis to trigger a sound in a particular location with one hand whilst altering its pitch, dynamic level and granularity with the other. The sequences were semi-improvised; Challis would 'place' a voice and the actor would spin round to look towards that location, however this 'placement' and the order of sounds changed each performance. This cat-and-mouse sequence would become more and more frenetic until the actor was ultimately overwhelmed by the voices now coming from all around him.

As well as enabling the operator to intuitively manipulate the pitch and granularity of the sounds, rapid movement and 'fluttering' of the hand created tonal and positional changes that would have been difficult to achieve by conventional means. The same was true during the performance of a complex and dynamic sound-effect that featured a chainsaw being wielded by one of the story's key characters. In this instance, Challis created a complex effect derived from a variety of sources (motorbikes, lathes, angle-grinders, wood-chippers) and used the Benemin to mix the composition live in response to the action on stage.

The sound for the chainsaw was derived from recordings of two motorbike engines and various mechanical grinders to simulate the chainsaw hitting flesh and bone. By placing a hand into one of the motorbike beams, an idling state could be suggested with a motor simply ticking over. Natural movements of the hand trying to stay still contributed to this undulating state through constant but subtle volume changes. A rapid gesture down into the beam instantly increased volume. Using another hand in the pitch-beam gave the impression of revving the chainsaw. This could be done subtly with minor hand adjustments or dramatically at the point of attack at which point 'sliding' into the adjacent beams provided various grinding impact sounds. The ability to 'slip' between two or more beams and trigger sounds in quick succession contributed to the creation of a strong bond between the character's actions and Challis's reactions. Or to put it another way a two way relationship was created; the actor did not just respond to the sounds, the sounds also responded to the actor. Furthermore, due to the semi-improvised nature of this interaction the accompaniment never became entirely standardised and the more familiar the performers became with the parameters, the freer they were able to experiment within them.

Being connected to every component of the sound made the overall experience closer to that of playing an instrument. From the start of the sound to its conclusion Challis needed to 
exercise judgment and skill in terms of adjusting the sound-state to complete the intended illusion. Having proximity sensors contributed greatly to this effect by picking up even the slightest movement. The constant monitoring of the hand's motion afforded great subtlety and variation in a most intuitive way, allowing delicate 'twittering' between voices at the beam's extremities whilst offering dramatic bursts across voices in much closer proximity. Another key benefit was the ability to quickly 'slide' between and across multiples beams, creating complex blends and textures.

\subsection{Case Study 3: An Evening with the Grand Guignol}

A suite of three short horror plays, An Evening with the Grand Guignol was directed by Richard Hand and performed to a theatre audience at the Aberystwyth Horror Film Festival in 2009. As with Dead by Dawn, live sound-design was employed to create a 'cinematic' soundtrack with sound performers working in close partnership with the cast. In contrast, there was less requirement for spot-effects and more requirement for ambient soundscapes which would often blur the boundaries between music and eerie stage atmosphere.

It was not envisaged that complex technologies would be required as it was entirely possible to support the onstage actions using conventional triggers (such as buttons and faders). However, there were clear opportunities where the introduction of uncertainty into the interaction would have sharpened the relationship between the onstage actions and matching sounds. Most notably within these was the production of a heart-beat pulse in the opening sequences which was achieved by sliding a fader rapidly up and down. This method did work but the physical action did not map well onto the resultant sound which was heavily amplified through a sub-woofer such that the audience could feel the sound. In hindsight a more effective approach could have been achieved using a force-sensitive device such that squeezing an object in a clenched fist would control the sound. The sound set for An Evening with the Grand Guignol has been revisited to test out this alternate approach and the relationship between performer and sound object is much more connected using this alternate method of triggering and control. A similar pressure-based approach to interaction was also retested on some of the sound sets that were used to create the organic eerie atmospheres. In the original version, drones and sound effects were controlled using buttons and faders whilst in the retest the same sounds were controlled using force-sensors thereby enabling triggering and expressivity to be achieved using the same device. As with the heart-beat test, the overall control of the sound was more apparent with the performer feeling more involved with the emerging soundscape.

\section{Design Considerations}

\subsection{Performance Behaviours}

The three case studies suggest ways in which interactive and novel technologies might be used to harness physical movement for the purposes of digital-Foley. In the same way that contrasting performance behaviours can be seen as significant in the design of digital musical instruments (Malloch et al 2006, Challis and Smith 2012) they can be seen as equally significant within a context of digital-Foley. Malloch et al. (2006) propose a model for this which defines a continuum of performance behaviours reaching from those that offer only minimal control through to those that are highly skilful, where each aspect of a sound's existence is subtly guided and shaped throughout the entire interaction. 
At one extreme, there are model-based behaviours that have highly deterministic outcomes where sounds are triggered and allowed to run their course. In musical terms, this would include the behaviour by which playback of a pre-recorded section of music is initiated, or by which a wholly generative process is begun. In the context of digital-Foley, this could describe the sound designer who edits and applies sound to prerecorded imagery or perhaps the pre-rendered sound effects that are tied to cues within a stage play.

Further across the continuum there are rule-based behaviours where the triggered sounds have scope for some level of change. Various parameters may be available to the performer but these are operating within predefined constraints such that successive performances might share many sonic qualities whilst also appearing to be unique. Of course, the number of parameters that are made available to the performer, along with the extent to which these can be freely altered, will dictate how varied the resulting musical pieces or soundscapes might ultimately become.

Lastly there are skill-based behaviours. With a musical instrument, these type of behaviours describe the way in which a performer can play individual notes whilst also achieving multiparametric control over key properties. In sonic terms, Smalley (1997) suggests that sounds can be described by their spectromorphology or how the spectrum changes over time. With this in mind, skill-based performance behaviours enable the performer to have more comprehensive control over the spectromorphic shape of the sounds they are creating.

As such, technologies that offers skill-based performance behaviours will be of significant value within a context of digital-Foley. How might this work in practice though? What would make for a more immersive interactive environment within a context of digitalFoley?

\subsection{Technologies}

The basic remit of current work-in-progress builds upon the techniques and technologies explored in previous theatrical productions and collaborations. However, for this project Challis and Dean are producing a live multimedia performance that incorporates video projection, music and digital sound effects, the parameters of which will be manipulated by the performers and Foley artists. In order to further explore the possibilities created by the integration of digital technology, this production will experiment with a range of sensors enabling the actors and Foley artists to trigger sampled or synthesised sounds and manipulate sonic parameters through direct physical contact or via more intuitive interactions.

It was observed that freedom to move quickly across numerous sound sources can be of great use, particularly if this can be achieved by intuitive and instinctive gestures. It was also identified that the natural uncertainty of small movement introduced subtle degrees of variation to certain sounds thereby adding further nuance to the skill-based performance interaction. Added to this, it was also identified that a multi-parametric approach to sound manipulation can be used to achieve complex sound transformations. Also, Norman (1998) would encourage designers to consider the affordances that the interaction might offer us, such that the action required has an intuitive mapping to the sonic outcomes being achieved.

Of the technologies explored within the case studies, those that offered touch-free interaction appeared to bring an engaging dynamic into the performance element; the lack of haptic feedback introducing levels of uncertainty that appeared to feed into the delicacy of the performance. Though infra-red technology was used in the case studies, the same effect could be achieved in a number of different ways. Indeed alternate approaches could 
also effectively free the performer from being tied to a specific location by the physical apparatus. As identified earlier though, there will also be occasions where sudden triggering of sounds will still be required. Touch-free approaches can be less effective than physical buttons and switches in these contexts where the natural haptic feedback of the device offers additional confirmation of closure. Force sensors make a useful alternative to conventional switches enabling sudden triggering of sounds (with tactile feedback confirming the action) but with the added benefit of velocity sensitivity.

\subsection{Key principles}

Using electronic and digital-Foley devices in projects such as Dead by Dawn has revealed a set of principles that demonstrate the potential and practicalities of adopting a process utilising digital-Foley techniques within a live performance context.

1. It facilitates a sonic dialogue between actor and Foley artist/musician (the performer does not just respond to the sound, the sound also responds to the performer).

2. Performers can react to subtle changes in the delivery of each show instead of providing and responding to a fixed element identically repeated every performance.

3. The level of interaction this process affords allows sonic outcomes to be achieved through intuitive mapping.

4. Skill-based performance behaviours enable the Foley artist to have more comprehensive control over the spectromorphic shape of the sounds they create.

5. Freedom to move quickly across numerous sound sources can be of great use, particularly if this can be achieved by intuitive and instinctive gestures.

6. The natural uncertainty of small movement introduces subtle degrees of variation to certain sounds thereby adding further nuance to the performance interaction.

7. A multi-parametric approach to sound manipulation can be used to achieve complex sound transformations.

8. Technologies that offer touch-free interaction bring an engaging dynamic into the performance element as the lack of haptic feedback introduces levels of uncertainty that feed into the delicacy of the performance.

\section{Realising the digital-Foley for Metropolis}

It is with these principles and previous experiences in mind that Challis and Dean are approaching their current performance project, a multimedia adaptation of the novel and film Metropolis. This production will consist of scenes from Lang's silent film, interspersed with sequences of live radio drama, animated projections, and theatrical interpretations of the events, sub-plots, and additional details included in Harbou's original novel (1927). The first part of this process has been to put together a palette of sound effects and develop the digital-Foley devices upon which they can be performed.

Live Foley effects performed alongside a musical accompaniment was a fairly conventional practice in early cinema. However, the standard and appropriateness of the 
Foley accompaniment varied greatly and tended to be inaccurate, overdone, and badly operated (see Bottomore 2001). The critics of the era identified two main problems. Firstly, although the Foley devices used were well established in the theatre, the operators employed in the cinemas consisted mainly of poorly paid boys who were neither skilled nor subtle in the exercise of their duties (ibid,133). Secondly, attempting to match the photographic realism on screen with a realistic diegetic soundscape was a virtually impossible task because the effects were all generated manually. As one critic put it, 'the sound artist would have to have as many hands as a centipede has legs, and about a carload of effects ...' (ibid,138). For these reasons the practice became less popular and gradually receded during the nineteentwenties. However, this early foray into film Foley did have its advocates. While the main priority they identify is the importance of rehearsal and subtlety, the critic Stephen Bush went so far as to suggest that sound effects needed to be considered from a psychological perspective: 'Each picture must be studied by itself and only such effects introduced as have a psychological bearing on the situation depicted on the screen' (ibid,135).

Bottomore interprets this reference to 'a psychological bearing' as an indication that Bush was calling for the inclusion of some sounds that were not directly linked to images on screen, and the exclusion of some sounds that were. Although this is certainly an interesting technique, Bush's terminology also prompts the consideration of how sound effects inform and shape the audience's experience. From this perspective, the sound effects are not simply produced in the name of verisimilitude to fill the sonic void of a silent medium, instead they share and contribute to the atmosphere, mood, and emotional milieu of the storyworld depicted. This potential Bush identifies provides a useful parameter to consider when composing a Foley accompaniment (digital or otherwise) for a silent film. In the Metropolis project it is a factor that has had a particularly important bearing upon how to design the sound that is in many ways the central character of the story; the noise created by the machines that power the city.

The two primary sources on which the project is based (Lang's film and Harbou's novel) provide the initial indicators and characteristics of this sonic environment. The images that accompany the opening moments of the film are pistons pumping, spinning wheels, ceramic insulators, a rotating prime collector, alternators and cogs (the multiplicity of which are highlighted with kaleidoscopic collage shots). Lang's film also features three machines that provide both setting and impetus for narrative progression. The first of these is the 'Moloch'; a huge steam driven machine powering pistons that transform into the mechanical teeth of a people eating god during a hallucination scene (see fig. 2). Twelve workers are positioned across the front of the machine where they perform a series of relentless mechanical gestures in order to operate it.

The second is 'Paternoster'; a one man machine cruelly designed to require three hands to operate (see fig. 3). Also referred to as 'the Crucifix Machine' (due to the position the operator may have to adopt) this dial based machine has three metal arms that have to be simultaneously moved in order to correspond with illuminated lights.

The final machine is the Heart Machine (see fig. 4); maintained and controlled by the most senior foreman (Grot) this is the machine upon which the running of all the other machines is contingent. In the final stages of the film the machine is accelerated to full power; an act of sabotage which sends it into overdrive, generating bolts of electricity before finally breaking to pieces.

Despite their silent rendering the depiction of these three machines at work carries and conveys a powerful sonic signature. In The Haunted Screen, Eisner goes so far as to suggest that imagery has an almost synesthetic affect on the viewer: 


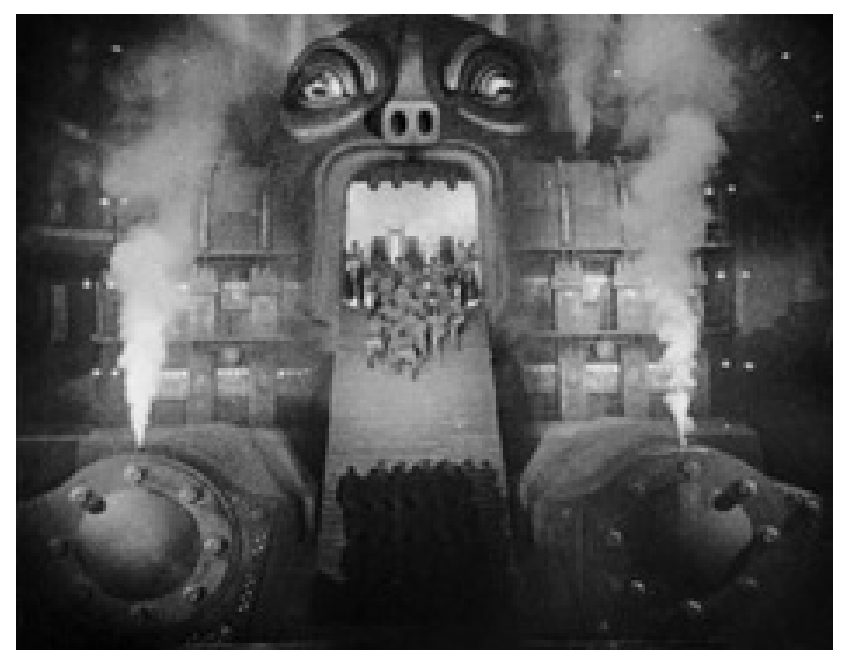

Figure 2 Moloch machine.

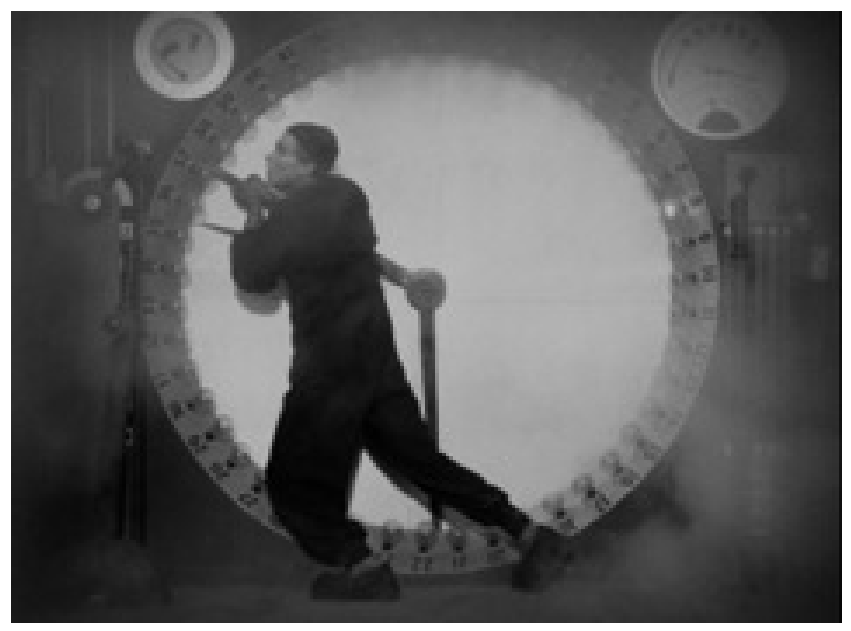

Figure 3 Paternoster machine.

"On the rare occasions when Lang relaxes his hold on the lighting effects, we suddenly notice that the machines have practically no raison d'etre: they do no more than compose a kind of moving background, an accompaniment, a sort of noises-off; in the noisy visual orchestration of Metropolis - a silent film - we can almost hear them ..." (Eisner 1952)

Harbou's novel also provides a number of descriptions detailing the noise created by these machines from a variety of perspectives. The most detailed of these is her account of the 'shift change'. The description Harbou gives of this moment is repeated three times during the novel and it provides an evocative and detailed articulation of the noise created and its sonic parallels: 


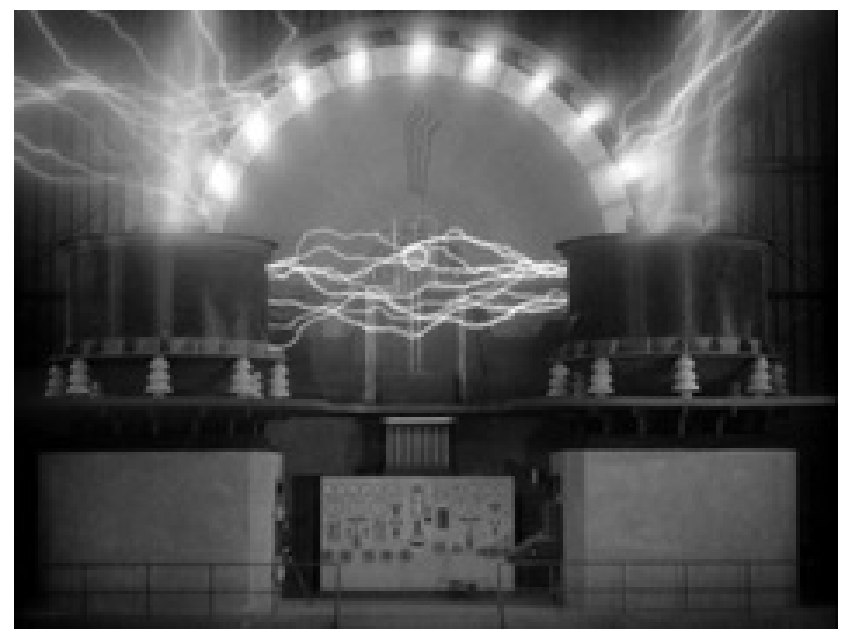

Figure 4 Heart machine.

\begin{abstract}
"Exhausted to death, drunken with weariness, he heard, with a sudden wince, that the air around him was becoming filled with an overpowering sound. It was an immeasurably glorious and transporting sound, as deep and rumbling as and more powerful than any sound on earth. The voice of the sea when it is angry, the voice of the falling torrents, the voice of very close thunder-storms would be miserably drowned in this Behmouth-din. Without being shrill it penetrated all walls and, as long as it lasted, all things seemed to swing in it. It was omnipresent, coming from the heights and from depths, being beautiful and horrible, being an irresistible command. It was high above the town. It was the voice of the town. Metropolis raised her voice. The machines of Metropolis roared; they wanted to be fed." (Harbou 1927, pp. 16, 108 and 140)
\end{abstract}

This combination of visual and descriptive material suggests components of the sonic palette with which to experiment as well as providing a framework in which to explore the physical relationship between the digital-Foley artist, the sounds they manipulate, and those that respond to them.

At the most fundamental level, there is the direct relationship between Foley artist and sound-object. In this respect, technology can be used to heighten the sense of physical connection between the two, thereby affording the sound-object a hitherto inaccessible palpable dimension. For example, a simple squeezing action can be mapped across a range that requires the Foley artist to exert only the most delicate of pressures at one end, while reaching extreme levels of a given parameter is so difficult that the Foley artist has to seemingly 'crush' the trigger-device to achieve maximum effect. This alternative method of triggering and control is one which we have experimented with when generating the sounds that aurally animate the heart machine and its destruction. When the machine is running smoothly its soothing pulsing hum can be triggered with soft rhythmical movements from the Foley artist. However, as it gradually spins out of control the operator is required to adopt ever more physically assertive playing techniques.

Breath can also be used to offer a range of manipulation that requires only gentle exhalation to one end of the spectrum whilst requiring the performer to blow as hard as they can to reach the maximum change. Such technology essentially converts the breathing process into an act which controls and manipulates sonic scales and textures in a manner 
comparable to a musician. For the purposes of this project the Foley artist's breath will be used to aurally encapsulate the steam belching, worker guzzling, Moloch machine. Another method used in these scenes draws on the electroacoustic work of Trevor Wishart (Vox Cycle 1990), a sonic artist who uses a phase vocoder to morph between sounds. By adapting this process with a realtime audio morphing plugin the Foley artist can blend audio sources to create hybrid sounds; morphing a human voice into the rattle of a machine gun, the revolution of pistons, or the hum of a machine.

Another interactive relationship that this way of working enables is between the Foleyartist and actors. In our adaptation the scene featuring the Paternoster machine will be performed live. This creates opportunities for the sound-production to be completed by an actor on stage, possibly using quite traditional and mechanical means, whilst the actions that they are required to perform are governed by the digital-Foley artist. Using a tablet or three simple dials, the digital-Foley artist can trigger the lights that dictate where the actor needs to move the three arms in order to produce the desired combination of sounds. Correctly completing these tasks will be a time sensitive operation and produce a sonorous and choric sound that juxtaposes the physical effort exerted. Resistance to movement within the interface could be of considerable value too. For example, by making it significantly harder (or easier) to physically work the machine the actor (and through them the audience) will further experience the strength sapping nature of this labour. In effect, the actor is presented as a tortured puppet remotely controlled by the languid finger movements of the Foley artist, sentenced to underscore their own faltering efforts with a soundscape of their own creation.

Lastly, there is the relationship between the Foley artist, the sound-object and the audience. Though there are various ways in which sound can be used to convey the nature and substance of these machines, it is also important that the audience 'feel' the power and control they wield. Low drones, rumbles and pulses played through subwoofer speakers are a very effective technique for creating a physiological connection between sound and audience. Similarly, panning sound across a stereophonic or quadraphonic field can be employed to disorientate the audience's senses. Through experimentation we have explored the potential of repurposing low-cost games controllers, such as the Nintendo Wii Remote (and Nunchuk), within these spatial contexts. As well as featuring two joystick controls and a variety of switches, such devices contain gyroscope sensors which can provide an intuitive method for mapping physical gestures to movement on a 2D plane. For instance, 'roll' could control stereo panning, whilst 'pitch' (in a directional rather than musical sense) could control vertical placement.

\section{Conclusion}

In 1937 Carlos Chavez published Towards a New Music, a publication that sought to discuss and promote the potential of electronic instruments. Chavez identifies and summarises the impact and importance of these technical advances in the following statement:

\footnotetext{
"Up to now, the sound-agents have been strings, columns of air, and plates and membranes. The procedures for obtaining vibrations from them have been, in general terms, rubbing, blowing, striking, and plucking ... Electric instruments of sound production offer the first case in history of a new musical instrument. They contain a new sound agent, a new manner of vibrating that agent, and a new means of controlling that vibration - in frequency (pitch), amplitude (intensity), and form (timbre)." (Chavez 1937)
} 
What Chavez predicts for the 20th Century has come full circle in the 21st century. The digital age we have entered has transfigured the way in which sonic material can be produced, manipulated, and played. Digitally captured audio samples can be controlled across numerous parameters through both traditional and innovative methods. Furthermore, the reduction in the level of manual interaction required opens up new possibilities for the physical manipulation of sound. In this respect, physical computing can enable the Foley artist to work with digitised 'concrete' sounds whilst also maintaining a sense of tangibility. Similarly, the ability to respond to actions unfolding in real time that digital-Foley allows is another key factor guiding the experiments in which we are currently engaged. It is the exploration of these possibilities that lies at the heart of the project we have termed 'digital-Foley for live performance'. The interfaces, interactions and sonic palettes are still emerging but as the project develops we are beginning to establish the founding principles and process through which we hope to establish our future working practice.

\section{Acknowledgement}

This paper is a revised and expanded version of a paper entitled 'Digital-Foley and Live Performance' presented at ArtsIT 2013, Milan, Italy, March 21-23, 2013. Challis, B. and Dean, R. (2013) Digital-Foley and Live Performance. In: Arts and Technology Third International Conference, Lecture Notes of the Institute for Computer Sciences, Social Informatics and Telecommunications Engineering, (116), (2013) pp. 65-72

\section{References}

Barbancho, I., Rosa-Pujazon, A., Tardon, L. J. and Barbancho, A. M. (2013) HumanĐComputer Interaction and Music. In: R. Bader (ed.) Sound - Perception Performance, Springer, pp. 367-389

Benveniste, S., Jouvelot, P., Lecourt, E. and Michel, R. (2009) Designing Wiimprovisation for Mediation in Group Music Therapy with Children Suffering from Behavioral Disorders. In: Proceedings of the 8th International Conference on Interaction Design and Children, ACM, pp.18-26

Bottomore, S. (2001) The Story of Percy Peashaker: Debates about Sound Effects in the Early Cinema. In: R. Abel \& R. Altman (eds.) The Sounds of Early Cinema, Indiana University Press, pp.129-142

Brooks, T., Camurri, A., Canagarajah, N. and Hasselblad, S. (2002) Interaction with shapes and sounds as a therapy for special needs and rehabilitation. In: Proceedings of 4th International Conference on Disability, Virtual Reality and Associated Technologies.

Challis, B.P. and Challis, K. (2008) An Infrared Sound and Music Controller for Users with Specific Needs, In: Proceedings of ArtAbilitation 200, pp. 339-345

Challis, B. P. and Smith, R. K. (2012) Assistive Technology and Performance Behaviours in Music Improvisation, In: Arts and Technology, Lecture Notes of the Institute for Computer Sciences, Social-Informatics and Telecommunications Engineering, Vol. 101 
Chavez, C. (1937) Towards a New Music, Da Capo Press, pp.138-139

Eisner L. H. (1952) The Haunted Screen: Expressionism in the German Cinema and the Influence of Max Reinhardt, Revised Edition (2003), University of California Press, p.235

Francese, R., Passero, I. and Tortora, G. (2012) Wiimote and Kinect: gestural user interfaces add a natural third dimension to HCI. In: Proceedings of the International Working Conference on Advanced Visual Interfaces, pp.116-123

Harbou, T. (1927) Metropolis, Wildside Press (2002 reprint)

Jung, D., Jensen, M. H., Laing, S. and Mayall, J. (2012) .cyclic.: An Interactive Performance Combining Dance, Graphics, Music and Kinect-Technology. In: Proceedings of the 13th International Conference of the NZ Chapter of the ACM's Special Interest Group on Human-Computer Interaction, pp. 36-43

Lang, F. (1927) Metropolis, UFA (2010 Restoration)

Malloch, J., Birnbaum, D., Sinyor, E. and Wanderley, M.(2006) Towards a New Conceptual Framework for Digital Musical Instruments, In: Proceedings of 9th International Conference on Digital Audio Effects, pp.49-52

Miller, J. and Hammond, T. (2010) Wiiolin: a virtual instrument using the Wii remote. In: Proceedings of New Instruments of Music Expression 2010, pp. 497-500

Mott, R. L. (1990) Sound Effects, Focal Press

Nagler, A.M. (1952) A Source Book in Theatrical History, Dover Publications, p.9

Norman, D. (1998) The Design of Everyday Things, MIT Press

Paine, G. (2007) Interfacing for Dynamic Morphology in Computer Music Performance, In: Proceedings of the Inaugural International Conference on Music Communication Science, pp.115-118

Rabey, D. I. (2003) Staging Crash: the sexualizing of language in action, Studies in Theatre and Performance, Vol. 23, No. 1, pp.41-54

Schofield, T., Vine, J., Higham, T., Carter, E., Atken, M. and Golding, A. (2013) Trigger shift: participatory design of an augmented theatrical performance with young people. In: Proceedings of the 9th ACM Conference on Creativity \& Cognition, pp.203-212

Senturk, S., Lee, S. W., Sastry, A., Daruwalla, A. and Weinberg, G. (2012) Crossole: A Gestural Interface for Composition, Improvisation and Performance using Kinect. In: Proceedings of New Instruments of Music Expression 2012

Smalley, D. (1997) Spectromorphology: Explaining sound-shapes, Organised Sound, Vol. 2, No. 2, pp.107-126

Wong, E. L., Yuen, W. Y. F. and Choy, C. S. T. (2008) Designing Wii Controller - A Powerful Musical Instrument In An Interactive Music Performance System. In: Proceedings of the 6th International Conference on Advances in Mobile Computing and Multimedia, pp.82-87

Yoo, M. J., Beak, J. W. and Lee, I. K. (2011) Creating Musical Expression using Kinect. In: Proceedings of New Instruments of Music Expression 2011 